\title{
APLICAÇÃO DA METODOLOGIA DE ANÁLISE E RESOLUÇÃO DE PROBLEMAS (MASP) EM UMA INDÚSTRIA MONTADORA AUTOMOTIVA
}

\author{
APPLICATION OF ANALYSIS AND PROBLEM SOLVING METHODOLOGY (MASP) IN AN \\ AUTOMOTIVE ASSEMBLY INDUSTRY
}

\author{
Hitalo Antunes Gaigher ${ }^{1} \&$ Rita de Cassia Feroni ${ }^{2 *}$ \\ ${ }^{12}$ Centro Universitário Norte do Espírito Santo da Universidade Federal do Espírito Santo. \\ ${ }^{1}$ hitaloag@gmail.com ${ }^{2 *}$ ritaferoni@gmail.com
}

\section{ARTIGO INFO.}

Recebido em: 12.11.2021

Aprovado em: 07.12.2021

Disponibilizado em: 08.12.2021

\section{Palavras-chave:}

Gestão de estoque; logística; MASP; MRP; resolução de problemas.

Keywords:

Stock management; logistics; MASP; MRP; problems resolution.

\section{*Autor Correspondente: Feroni, R. de C. \\ RESUMO}

O setor automotivo vem crescendo rapidamente. Assim, as empresas do ramo buscam mecanismos para melhoria da gestão de seus produtos e processos, a fim de garantir o alcance das metas e redução de custos. $\mathrm{O}$ presente artigo por meio de uma pesquisa-ação, levantou as causas do alto índice de falta de materiais no processo de manufatura em uma montadora automotiva. As informações referentes ao estudo foram levantadas via sistema de informação da empresa e posteriormente foram mapeadas e propostas soluções/ações para as causas do problema. Para isso, foram aplicadas algumas ferramentas de gestão da qualidade como Metodologia de Análise e Solução de Problemas - MASP, diagrama de causa-efeito, cinco porquês, 5W2H e lista de verificação. Como resultado, foi possível reduzir as causas que geravam diretamente o atraso de fornecedores no processo de abastecimento, alcançando, nos primeiros sete meses subsequentes a implementação dos planos de ação, uma redução de 90,14\% nos atrasos de fornecedores, justificando assim a eficácia das ações propostas pela pesquisa.

\begin{abstract}
The automotive sector has been growing rapidly. Thus, companies in the industry seek mechanisms to improve the management of their products and processes, in order to guarantee the achievement of goals and cost reduction. The present article, through action research, raised the causes of the high rate of lack of materials in the manufacturing process in an automotive manufacturer. The information related to the study was collected via the company's information system and subsequently mapped and proposed solutions / actions for the causes of the problem. For that, some quality management tools were applied, such as Methodology for Analysis and Problem Solving - MASP, cause-effect diagram, five whys, $5 \mathrm{~W} 2 \mathrm{H}$ and checklist. As a result, it was possible to reduce the causes that directly caused supplier delays in the supply process, achieving, in the first seven months following the implementation of action plans, a $90.14 \%$ reduction in supplier delays, thus justifying the effectiveness of the actions proposed by the research.
\end{abstract}


Citação (APA): Gaigher, H. A. \& Feroni, R. de C. (2021). Aplicação da metodologia de análise e resolução de problemas (MASP) em uma indústria montadora automotiva. Brazilian Journal of Production Engineering, 7(5), 183-193.

\section{INTRODUÇÃO}

O processo de aquisição de materiais tem uma participação importante nos resultados positivos de uma organização, com vista à lucratividade e posição competitiva no mercado. De Paula e Feroni (2021) destacam que, uma gestão eficiente do processo de logística é fundamental para o equilíbrio financeiro de uma empresa, podendo ser obtido por meio do adequado abastecimento, planejamento, reaproveitamento de materiais e satisfação dos clientes.

A gestão de estoques, destaca-se como atividade essencial para o cumprimento das funções logísticas (Rodrigues \& Santin, 2004), contribuindo, quando eficiente, para a melhoria do nível de serviço, redução de custos empresariais (Dorregão et al., 2017) e eficiência econômica (Costa \& Guarnieri, 2018). O planejamento de recursos materiais (MRP) torna-se uma ferramenta importante neste sentido, surgindo como uma ferramenta que determina adequadamente os componentes necessários para satisfazer a produção de um produto (Acosta et al., 2019) e, em circunstâncias ideais, o programa libera ordens de pedidos de itens que devem ser adquiridos para suprir a demanda em momento oportuno (Tanna \& Vyas, 2017), eliminado assim, possíveis interrupções por ausências de peças nas linhas de produção (Guerra et al., 2014).

Uma ferramenta bastante utilizada para verificar e solucionar problemas na gestão de estoque é a Metodologia de Análise e Solução de Problema (MASP). Pires (2013) destaca que a MASP é um método de solução de problemas concebido de forma ordenada, sendo composto de passos e subpassos que são predefinidos e destinados a escolha de um problema, com análise das suas causas, determinação e planejamento de ações que constituem uma solução, verificação do resultado da solução e, por fim, a geração e disseminação de aprendizado decorrido de sua aplicação. Estudo proposto por Braga e Borges (2019) mostraram que a MASP é capaz de identificar problemas, proteger o cliente, analisar e validar potenciais causas raízes do problema, elaborar plano de ação para eliminar e prevenir novas ocorrências, padronizar e validar se todo o processo foi realizado de forma eficaz e eficiente.

No estudo de Santos et al. (2012), com o objetivo de abordar um problema e aplicar a metodologia MASP na busca da solução para a melhoria contínua na produção de produtos domésticos em uma empresa vidreira, os resultados mostraram um aumento nos rendimentos e na qualidade da produção, ocasionando ganhos financeiros para a empresa pesquisada. Santos e Gonçalves (2016) mostrou que a aplicação da ferramenta MASP possibilitou uma amenização nos estoques excessivos de produtos, contribuindo com um melhor desempenho das atividades, enquanto Rezende et al. (2019), ao utilizar a metodologia MASP em conjunto com as ferramentas Brainstorming, Folha de verificação, Diagrama de causa e efeito, Gráfico de Pareto e 5W1H, minimizaram o problema de desperdício de papel A4 usados na impressão, ao eliminar as causas, erro do operador, bandeja da impressora com defeito e a mudança repentina do conteúdo do documento.

Neste contexto, o presente estudo tem como objetivo a utilização da metodologia MASP em uma montadora automotiva, a fim de identificar e solucionar problemas existentes no abastecimento de materiais.

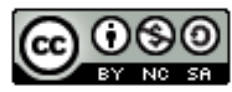


Citação (APA): Gaigher, H. A. \& Feroni, R. de C. (2021). Aplicação da metodologia de análise e resolução de problemas (MASP) em uma indústria montadora automotiva. Brazilian Journal of Production Engineering, 7(5), 183-193.

\section{Metodologia}

A empresa em estudo é uma fabricante de carrocerias de ônibus e micro-ônibus localizada no sudeste do Brasil, que conta com aproximadamente 1000 colaboradores divididos entre os setores de fabricação de peças em fibra, fabricação de peças metálicas, linhas de montagem, logística e setor administrativo. Por questões de sigilo, serão suprimidas do presente trabalho, informações que possam identificar e detalhar a empresa em estudo.

Como etapa inicial, foram feitas pesquisas em documentos da empresa, base de dados e entrevistas com os planejadores de materiais e gestores da área logística, os quais são responsáveis pela gestão de estoque. Seguindo metodologia similar a proposta por Campos (1992), as etapas seguintes do trabalho seguem com a aplicação da metodologia MASP.

Como primeira etapa do MASP, realizou-se a "Identificação do problema", a partir das principais áreas envolvidas e, posteriormente, identificou-se, definiu-se e avaliou-se os principais indicadores de desempenho, registros, formulários e planilhas da empresa. Dando continuidade, a segunda etapa consiste na "Observação contínua" do processo, com o objetivo de encontrar as características do problema através da coleta de dados. Em seguimento, realizou-se um brainstorming com a equipe definida, para validar as observações sobre o problema.

$\mathrm{Na}$ terceira etapa, referente a "Análise do problema", foram identificadas as causas que influenciam no problema. Para estruturar esse processo utilizou-se a ferramenta Diagrama de Causa e efeito (Gráfico de Ishikawa). Na quarta etapa estipulou-se um "Plano de Ação" para resolução do problema e melhorar a gestão de materiais. Criou-se planos de ação norteados pela técnica gerencial 5W2H, referente aos seguintes parâmetros: o que (what), por que (why), onde (where), quando (when), quem (who), como (how) e quanto custa (how much).

A quinta etapa, “Ação”, caracteriza-se por apresentar o Plano de Ação aos gestores por meio da realização de um brainstorming. As ações foram propostas com base no 5W2H. Esta etapa se caracteriza por aplicar as ações necessárias para a minimização do problema. Nesta etapa foi desenvolvida uma ferramenta em Visual Basic for Application (VBA) para disparo de e-mail automático.

A etapa de "Verificação" no andamento dos pedidos foi realizada diariamente por meio do indicador de peças faltantes na linha de produção, a partir dos relatórios fornecidos do MRP e acompanhamento dos gestores na linha de produção.

Após a verificação e aprovação da ferramenta, definiu-se junto à equipe, a etapa de "Padronização" e inserção da ferramenta no cronograma de atividades a serem desempenhadas pelo planejamento. Por fim, na etapa de "Conclusão", retornou-se a cada etapa e analisou-se os resultados obtidos. Nesta última etapa, foi recapitulado, verificado, reavaliado e revistos os problemas levantados no presente trabalho, a fim de pontuar erros e acertos, refletir sobre as atividades propostas e garantir a melhoria contínua do processo.

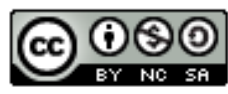


Citação (APA): Gaigher, H. A. \& Feroni, R. de C. (2021). Aplicação da metodologia de análise e resolução de problemas (MASP) em uma indústria montadora automotiva. Brazilian Journal of Production Engineering, 7(5), 183-193.

\section{RESULTADOS E DISCUSSÃO}

Os resultados encontram-se subdivididos a partir das etapas da metodologia MASP supracitadas.

\subsection{IDENTIFICAÇÃO DO PROBLEMA}

Em entrevista com os gestores da empresa, verificou-se que existia um problema relacionado a falta de material na linha de produção que ocasionava uma série de desvantagens para toda sistemática do gerenciamento, tais como: a perda de nível de serviço ao cliente, dificuldade para ressuprimento, dificuldade no planejamento e possíveis paradas de produção.

Neste sentido, um brainstorming com a equipe de logística e planejamento foi realizado onde as ideias sobre possíveis causas do problema foram explanadas e registradas, sendo elas, (i) atraso de fornecedores no fornecimento dos insumos na data correta do pedido de compra; (ii) erro de estoque, com divergências entre saldo informado no sistema de controle e estoque físico nos depósitos da empresa; (iii) complementação de engenharia, com adição ou retirada de componentes, pela engenharia, dos projetos de veículos em andamento; (iv) problemas de qualidade, com itens em desacordo com os padrões estabelecidos pela empresa; (v) peças danificadas durante as operações de abastecimento e montagem e reprovadas pela engenharia da qualidade; (vi) divergência no recebimento, com peças faltantes identificadas durante o processo de conferência pelo recebimento da logística. A Figura 1 mostra um gráfico com a frequência coletada a partir de indicadores analisados diariamente na empresa para cada uma das causas do problema mencionadas anteriormente pelos gestores.

Figura 1. Problemas identificados no abastecimento de materiais

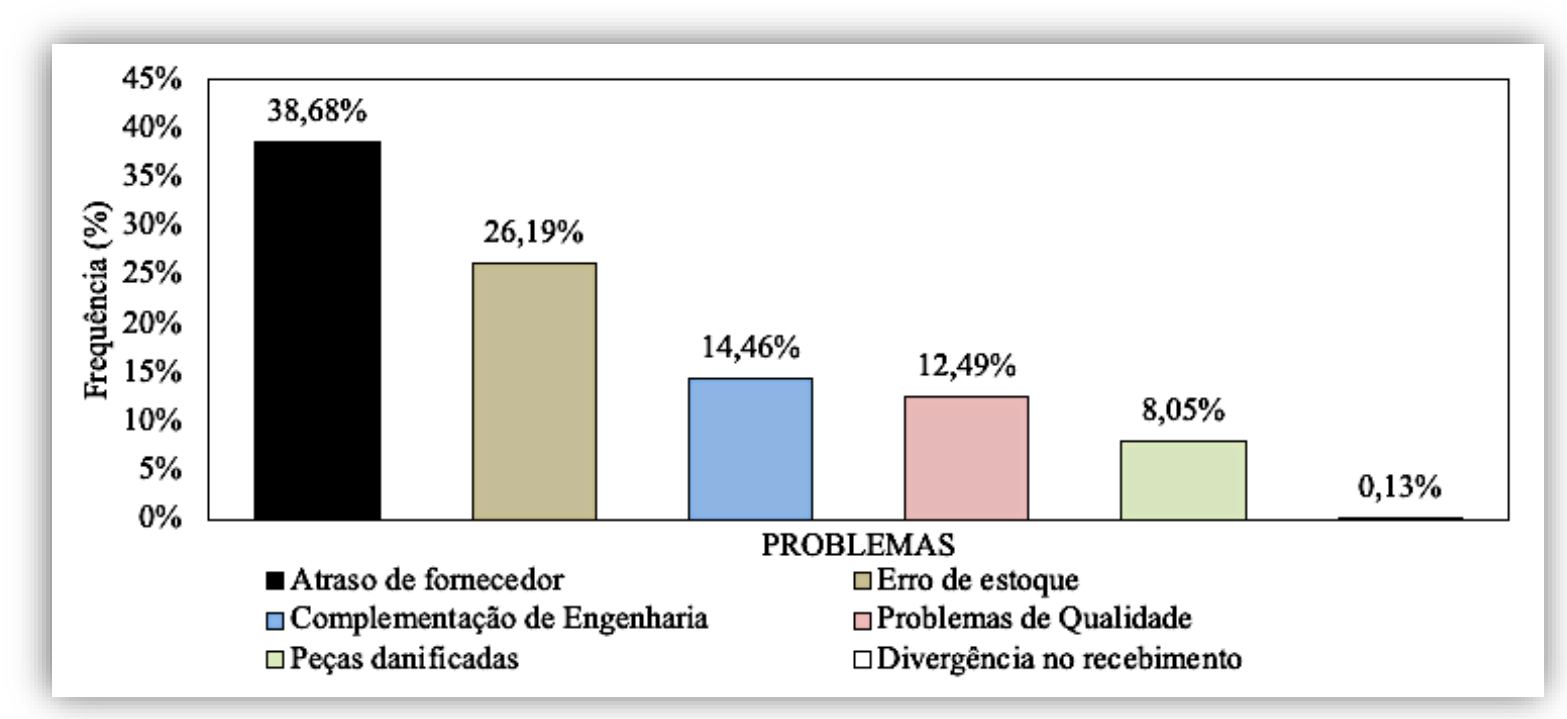

Fonte: Autores (2021).

Diante do exposto na Figura 1, constatou-se que 38,68\% do total de itens faltantes na linha de produção são ocasionadas por atrasos de fornecedores. Levando-se em consideração que o objetivo da empresa é alcançar $100 \%$ do nível de serviço, este valor enfatiza a realização de uma pesquisa mais detalhada deste problema.

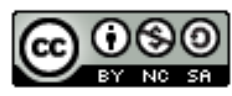

Esta obra está licenciada com uma Licença Creative Commons Atribuição-Não Comercial-Compartilha Igual 4.0 Internacional. Brazilian Journal of Production Engineering, São Mateus, Editora UFES/CEUNES/DETEC. 
Citação (APA): Gaigher, H. A. \& Feroni, R. de C. (2021). Aplicação da metodologia de análise e resolução de problemas (MASP) em uma indústria montadora automotiva. Brazilian Journal of Production Engineering, 7(5), 183-193.

Para finalizar a primeira etapa do MASP, foram definidas, em reunião, as pessoas que fariam parte da equipe responsável pelo estudo do problema, sendo elas, o coordenador de logística, o supervisor de materiais e três analistas de planejamento de materiais.

\subsection{OBSERVAÇÃO DO PROBLEMA}

A segunda etapa, observação do problema, é responsável por fazer a descoberta das características do problema através da coleta dos dados. Nele procura-se observar o problema sobre vários aspectos, tais como: tempo, local, tipo, sistema e indivíduo, estratificando os dados obtidos e sobre os aspectos específicos, como: temperatura ambiente, o treinamento dado ao pessoal, equipe responsável, entre outros. A coleta de dados foi baseada nos dados de paradas na linha de produção dos períodos disponibilizados pela empresa, correspondendo ao período de 14/01/2020 a 31/05/2020. Dados adicionais coletados através de entrevistas também foram utilizados.

Foram observadas as seguintes falhas relacionadas à atividade de abastecimento da linha de produção: mão-de-obra desfalcada, falha no sistema de entrega dos pedidos aos fornecedores, falha na comunicação, sistema de cobrança manual e complexa dos pedidos de compra, reprogramação da linha de montagem, falha no planejamento de materiais e demanda. Atrasos de entrega das ordens de compra pelos fornecedores também foi uma causa raiz identificada no trabalho de Treter et al. (2013), onde foi proposto um plano de ação.

\subsection{ANÁLISE DO PROBLEMA}

Nesse processo, são identificadas as causas reais que influenciam no problema "atraso de fornecedores". A ferramenta diagrama de causa e efeito (Figura 2) foi utilizada nessa etapa a fim de identificar, classificar e expor com clareza as possíveis e prováveis causas de um determinado efeito, uma vez que ao ser utilizada no estudo de Vieira et al. (2015), possibilitou aos autores verificar as causas raízes dos atrasos na entrega de materiais, buscando identificar as causas que mais impactam no problema analisado.

A partir das cinco categorias definidas por: método, meio ambiente, máquinas, medida, pessoas e materiais, a Figura 2 demonstra as potenciais causas raiz, sendo elas: elevando número de pedidos de compra, alterações na programação, cobrança manual de pedidos, atrasos na inserção de ordens de produção, falha no planejamento de materiais, falta de mão de obra, mão de obra sem orientação, equipamentos ultrapassados e lentos, falhas no sistema, capacidade de recebimento e escassez de matéria prima.

Partindo desse ponto, o foco do estudo é analisar quais dessas causas impacta mais fortemente o problema analisado e definir um plano de ação para que as mesmas sejam sanadas ou minimizadas.

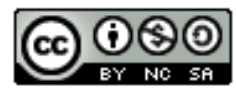


Citação (APA): Gaigher, H. A. \& Feroni, R. de C. (2021). Aplicação da metodologia de análise e resolução de problemas (MASP) em uma indústria montadora automotiva. Brazilian Journal of Production Engineering, 7(5), 183-193.

Figura 2. Diagrama de Causa e Efeito - Atraso de fornecedores

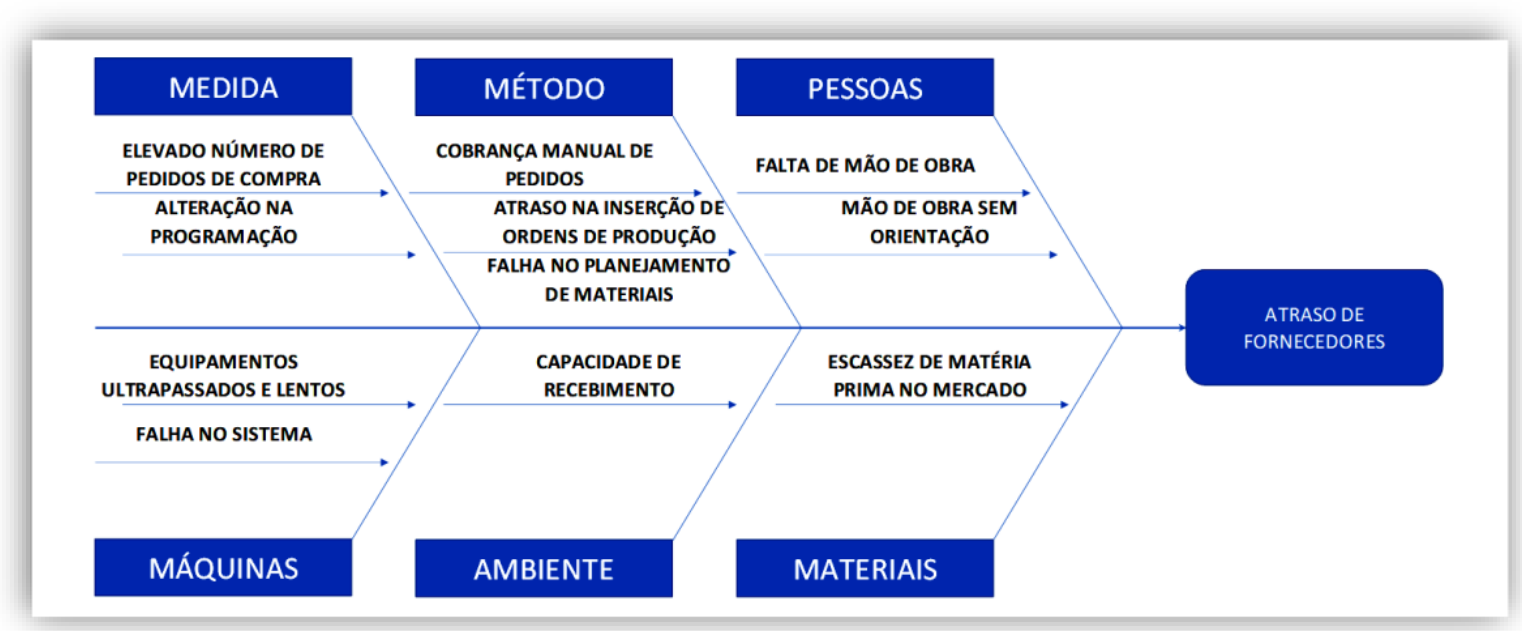

Fonte: Autores (2021).

Após as verificações expostas acima, as informações foram validadas e discutidas em um brainstorming com os participantes do estudo. Após a análise das causas fundamentais, seguiuse para o próximo passo da metodologia, o Plano de ação.

\subsection{Plano de aÇão}

Para a elaboração do plano, a metodologia deve conter informações como: identificação sobre o tipo de ação - causa ou efeito, os efeitos colaterais da causa, tempo da ação e por fim, o custo para implantação da ação proposta. Após a confirmação das causas fundamentais que afetam o atraso de fornecedores, levantou-se um plano de ação. Para melhor detalhamento foi utilizada o $5 \mathrm{~W} 2 \mathrm{H}$, no qual foi possível identificar variáveis como: por que a ação será proposta, quem será o responsável, quando a ação será realizada, como ela será feita, onde ela será realizada e por fim quanto vai custar para sua solução. O Quadro 1 mostra o plano de ação para o presente estudo.

Quadro 1. Plano de ação

\begin{tabular}{|c|c|c|c|c|c|}
\hline O que? & Como? & Por que? & Quem? & Quando? & Quanto? \\
\hline $\begin{array}{c}\text { Inserir ordens de } \\
\text { produção no } \\
\text { sistema }\end{array}$ & $\begin{array}{c}\text { Inserção das ordens de produção } \\
\text { no sistema com 4 semanas de } \\
\text { antecedência }\end{array}$ & $\begin{array}{c}\text { Reduzir o atraso no } \\
\text { planejamento de } \\
\text { materiais }\end{array}$ & $\begin{array}{c}\text { Planejamento } \\
\text { integrado }\end{array}$ & Semanal & Sem ônus \\
\hline $\begin{array}{c}\text { Planejamento de } \\
\text { materiais }\end{array}$ & $\begin{array}{c}\text { Realização do planejamento } \\
\text { semanal com antecedência de 4 } \\
\text { semanas }\end{array}$ & $\begin{array}{c}\text { Reduzir perda no } \\
\text { leadtime devido } \\
\text { atraso no } \\
\text { planejamento de } \\
\text { materiais }\end{array}$ & $\begin{array}{c}\text { Analista de } \\
\text { planejamento }\end{array}$ & Diário & Sem ônus \\
\hline $\begin{array}{c}\text { Auditoria de } \\
\text { parâmetros }\end{array}$ & $\begin{array}{c}\text { Auditoria de parâmetros no sistema } \\
\text { SAP }\end{array}$ & $\begin{array}{c}\text { Evitar parâmetros de } \\
\text { planejamento } \\
\text { incorretos }\end{array}$ & $\begin{array}{c}\text { Analista de } \\
\text { planejamento }\end{array}$ & Mensal & Sem ônus \\
\hline $\begin{array}{c}\text { Ferramenta para } \\
\text { disparo de e-mail } \\
\text { automático }\end{array}$ & $\begin{array}{c}\text { Elaboração de uma ferramenta de } \\
\text { disparo automático de e-mail }\end{array}$ & $\begin{array}{c}\text { Reduzir atraso na } \\
\text { entrega dos pedidos }\end{array}$ & $\begin{array}{c}\text { Analista de } \\
\text { planejamento }\end{array}$ & Semanal & Sem ônus \\
\hline $\begin{array}{c}\text { Verificação de } \\
\text { itens bloqueados } \\
\text { com necessidade }\end{array}$ & $\begin{array}{c}\text { Relatórios diários por meio de Jobs } \\
\text { planejamento devido } \\
\text { bloqueio de materiais }\end{array}$ & $\begin{array}{c}\text { Reduzir o atraso no } \\
\text { planejamento }\end{array}$ & Diário & Sem ônus \\
\hline
\end{tabular}

Fonte: Autores (2021).

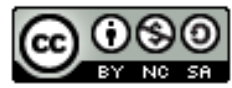

Esta obra está licenciada com uma Licença Creative Commons Atribuição-Não Comercial-Compartilha Igual 4.0 Internacional. Brazilian Journal of Production Engineering, São Mateus, Editora UFES/CEUNES/DETEC. 
Citação (APA): Gaigher, H. A. \& Feroni, R. de C. (2021). Aplicação da metodologia de análise e resolução de problemas (MASP) em uma indústria montadora automotiva. Brazilian Journal of Production Engineering, 7(5), 183-193.

Nesta etapa finaliza-se todo o processo de planejamento da Metodologia de Análise e Solução de Problemas - MASP. A próxima etapa evidenciará a execução do Plano de Ação, que dependeu da colaboração de todos envolvidos na pesquisa.

\subsection{EXECUÇÃO DO PLANO DE AÇÃO}

Nesta etapa foi apresentado o plano de ação aos gestores por meio da realização de um brainstorming, a fim de conscientizá-los sobre a execução do plano. A primeira medida a ser tomada está relacionada a inserir ordens de produção no sistema, onde passou-se a inserir as ordens de produção no MRP semanalmente às segundas-feiras, pelo planejamento integrado, conforme padronizado.

A etapa seguinte diz respeito ao planejamento de materiais, onde estipulou-se agilidade no planejamento de materiais comprados um dia após a inserção das ordens de produção no sistema e a cobrança ao setor de compras para que as requisições de compra fossem convertidas em ordens de compra no mesmo dia.

A terceira etapa relaciona-se a auditoria de parâmetros, onde devem ser analisados os parâmetros de materiais comprados mensalmente, a fim de verificar se estão dentro dos padrões estabelecidos pela equipe. Houve a definição de um colaborador para que seja responsável pelo workflow, com o intuito de definir corretamente os parâmetros desde a criação dos códigos.

Como etapa seguinte desenvolveu-se uma ferramenta para disparo de e-mail automático, como uma ferramenta de apoio mais acessível e de fácil compreensão aos usuários em linguagem de programação Visual Basic for Application (VBA). O algoritmo visa simplificar as etapas de disparo de e-mail com cobranças aos fornecedores externos, com base no banco de dados de pedidos pendentes, possibilitando, assim, a cobrança em massa de todos os pedidos de forma automatizada e simples. Foram necessárias três informações, sendo elas, endereço de e-mail, assunto e corpo do e-mail. A Figura 3 demonstra o layout simplificado utilizado no programa.

Por fim, a última etapa caracterizou-se pela verificação de itens bloqueados com necessidades, onde, a partir da necessidade estabelecida pelo sistema, deverão ser analisados diariamente se houve a ocorrência de materiais com necessidade de abastecimento com bloqueio, seja ele por: workflow, bloqueio de compras, bloqueio de lista técnica pela engenharia ou bloqueio logístico.

Figura 3. Ferramenta em Excel para disparo de e-mail

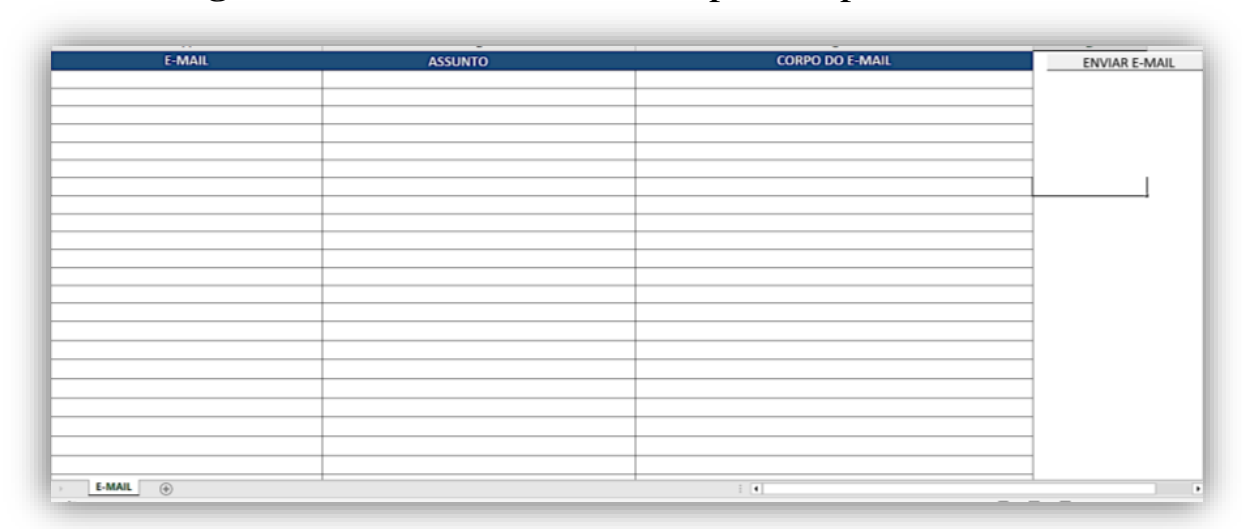

Fonte: Autores (2021). 
Citação (APA): Gaigher, H. A. \& Feroni, R. de C. (2021). Aplicação da metodologia de análise e resolução de problemas (MASP) em uma indústria montadora automotiva. Brazilian Journal of Production Engineering, 7(5), 183-193.

\subsection{VERIFICAÇÃO DOS RESULTADOS}

Esta etapa objetivou verificar a execução do plano de ação. Para o presente trabalho esta etapa foi realizada no período de 01/07/2020 a 28/02/2021. Assim, verificou-se que, as causas relacionadas à falta de material começaram a ser minimizadas.

Observou-se que, (i) a intensificação na cobrança da inserção de ordens de produção no sistema MRP no prazo correto permitiram que os itens fossem planejados no tempo correto, respeitando o leadtime; (ii) o planejamento de materiais nos dias posteriores garantiu ganhos de tempo nas operações, permitindo que o fornecedor visualizasse os pedidos dentro do prazo correto; (iii) a análise mensal de parâmetros permitiu que não houvessem falhas no planejamento de materiais devido a parâmetros incorretos; (iv) a análise diária do relatório de materiais bloqueados com necessidade permitiu que os atrasos no planejamento fossem minimizados; (v) a implementação da ferramenta de disparo automático de e-mail baseado na carteira de pedidos permitiu uma redução do tempo do colaborador na cobrança de pedidos; (vi) houve aumento da eficiência e eficácia na cobrança de pedidos devido a simplificação de etapas complexas e repetitivas do processo de cobrança de pedidos. A Figura 4 mostra os indicadores de falta de peças ocasionadas pelos atrasos dos fornecedores na etapa de verificação.

Analisando o indicador da falta de peças ocasionadas pelo atraso de fornecedores, pode-se observar que houve uma redução de $90,14 \%$, considerando o mesmo período (fev./2020 e fev./2021). Destaca-se que no período de março a abril de 2020, houve férias coletivas na empresa devido a pandemia do Covid-19. Nos últimos meses pode-se perceber um leve aumento na frequência do indicador, fato devido à fatores externos, como a falta de matéria prima no mercado, redução na mão de obra, ambos devido a pandemia, o que dificultou o abastecimento de materiais pela logística.

Figura 4. Acompanhamento da falta de materiais devido atraso de fornecedores

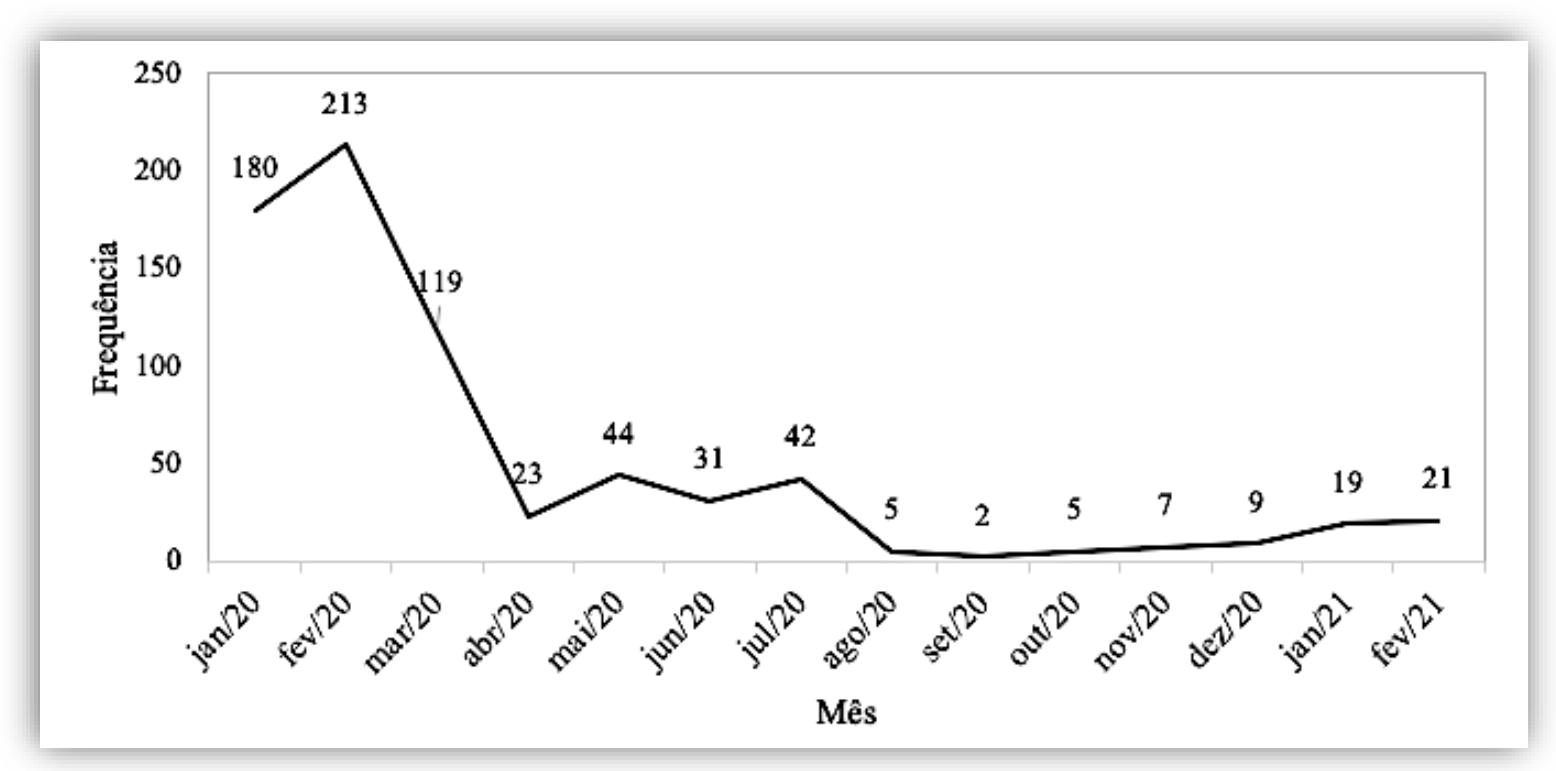

Fonte: Autores (2021).

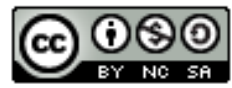

Esta obra está licenciada com uma Licença Creative Commons Atribuição-Não Comercial-Compartilha Igual 4.0 Internacional. Brazilian Journal of Production Engineering, São Mateus, Editora UFES/CEUNES/DETEC. 
Citação (APA): Gaigher, H. A. \& Feroni, R. de C. (2021). Aplicação da metodologia de análise e resolução de problemas (MASP) em uma indústria montadora automotiva. Brazilian Journal of Production Engineering, 7(5), 183-193.

Em uma visão global, após a execução do plano de ação, os volumes de falta de materiais na linha de produção ocasionados pelo atraso de fornecedores foram reduzidos, facilitando as operações, propiciando um atendimento mais eficiente à linha de produção e, consequentemente, ao cliente final.

\subsection{PADRONIZAÇÃO DOS PROCEDIMENTOS}

Verificadas as melhorias ocasionadas pela execução do plano de ação, elaborou-se um modelo de Lista de Verificação (Quadro 2) para o controle e acompanhamento dos procedimentos adotados no plano de ação, similar ao realizado no estudo de Santos e Gonçalves (2016). A lista de verificação consiste em coletar os dados definidos no plano de ação, de modo simplificado e organizado. A ideia é que a ferramenta seja de fácil preenchimento contendo vários itens a serem verificados rapidamente. Assim, a ferramenta dará suporte ao gestor ou ao representante do setor para evitar alterações prejudiciais ao bom desempenho da empresa.

Quadro 2. Lista de Verificações para controle dos processos.

\begin{tabular}{|c|c|c|c|c|}
\hline \multicolumn{5}{|c|}{ LISTA DE VERIFICAÇÃO } \\
\hline \multirow{3}{*}{ ATIVIDADE } & \multicolumn{2}{|c|}{ DATA: } & \multicolumn{2}{|c|}{ SEMANA: } \\
\hline & \multicolumn{2}{|c|}{$\begin{array}{c}\text { Atende ao } \\
\text { padrão? }\end{array}$} & \multirow[b]{2}{*}{ Problema } & \multirow[b]{2}{*}{ Ação Tomada } \\
\hline & Sim & Não & & \\
\hline \multicolumn{5}{|l|}{ Inserção das ordens de produção no MRP } \\
\hline \multicolumn{5}{|l|}{ Planejamento dos materiais } \\
\hline \multicolumn{5}{|l|}{ Auditoria de parâmetros } \\
\hline \multicolumn{5}{|l|}{ Liberação de Workflow } \\
\hline \multicolumn{5}{|l|}{ Envio do e-mail automático } \\
\hline Verificação dos itens bloqueados & & & & \\
\hline
\end{tabular}

Fonte: Autores (2021).

\subsection{Conclusĩo da Metodologia}

Inicialmente, identificou-se que o problema mais relevante para a logística é a falta de materiais no abastecimento da linha de produção, os quais interferiam diretamente no nível de serviço prestado ao cliente, refletindo negativamente nas variáveis tempo, disponibilidade de atendimento, custos e desempenho das atividades logísticas.

Após observação e análise do problema, foi possível identificar as possíveis causas que motivavam os atrasos dos fornecedores na entrega dos pedidos. Com intuito de minimizar ou eliminar as causas geradoras do problema, elaborou-se um plano de ação, ao qual foi executado com apoio dos colaboradores participantes do estudo. Foi verificado e validado os resultados obtidos com a execução do plano de ação e, por fim, adaptou-se à rotina da empresa uma lista de verificação diária para controle e desempenho das atividades.

O plano de ação deve ser revisto constantemente e deve-se transferir as informações para um documento, permitindo um acompanhamento adequado. Havendo a inserção de envolvidos na execução do projeto, deverão receber uma cópia com suas respectivas atividades e informações

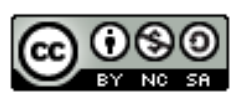


Citação (APA): Gaigher, H. A. \& Feroni, R. de C. (2021). Aplicação da metodologia de análise e resolução de problemas (MASP) em uma indústria montadora automotiva. Brazilian Journal of Production Engineering, 7(5), 183-193.

relevantes, adequadamente listadas, para o andamento do plano de ação. Esta fase é importante para retroalimentar os futuros processos de criação com os aprendizados adquiridos.

\section{CONSIDERAÇões Finais}

O processo de aquisição de materiais deve atentar-se a qualidade na execução de seus serviços, buscando a eficácia e a eficiência dos mesmos para assim satisfazer as necessidades da empresa. Neste sentido, o presente trabalho aplicou a metodologia MASP em uma montadora automotiva, a fim de identificar e solucionar problemas existentes no abastecimento de materiais.

Após o estudo dos indicadores presentes na empresa para avaliar o processo e um brainstorming com os gestores foi possível identificar o problema chave "atraso de fornecedores" e a necessidade de aplicar um método para resolver o problema da falta de material na linha de produção. Assim, o MASP se mostrou como uma alternativa viável e simples para que os planejadores de materiais minimizem o problema de falta de material, e em conjunto com ferramentas desenvolvidas na presente pesquisa, sendo elas, uma ferramenta em Excel para disparo de e-mail e uma lista de verificação, foi possível reduzir, em um ano, a falta de materiais devido atraso de fornecedores em 90,14\%, proporcionando, clareza, agilidade, economia e qualidade ao processo. Adicionalmente, a metodologia utilizada no presente trabalho e as ferramentas geradas não se limitam a presente pesquisa, podendo ser utilizada como referência por outros pesquisadores.

\section{REFERÊNCIAS}

Acosta, A. P. V, Mascle, C., \& Baptiste, P. (2020). Applicability of Demand-Driven MRP in a complex manufacturing environment. International Journal of Production Research, 58(14), 4233-4245.

Braga, N.E., \& Borges, F.H. (2019, Dezembro). A utilização da metodologia MASP: estudo de caso em uma indústria do setor de autopeças automotiva. Anais do IX Congresso Brasileiro de Engenharia de Produção, Ponta Grossa, PR, Brasil.

Campos, V. F. (1992). Controle da Qualidade Total. Rio de Janeiro: Editora Bloch.

Costa, C. D. F., \& Guarnieri, P. (2018). Gestão da aquisição e dos estoques de medicamentos: estudo de caso no Hospital Universitário de Brasília (HUB). Revista Foco, 11(2), 28-52.

de Paula, J. C. M., \& de Cassia Feroni, R. (2021). Use of the PDCA cycle and milk run application in a reverse logistics process in a food industry. Brazilian Journal of Production Engineering-BJPE, 7(2), 16-30.

Dorregão, R., Schlickmann, F., \& Soethe, A. B. (2017, Junho). Gestão do estoque obsoleto de uma indústria de implementos rodoviários. I Congresso Sul Catarinense de Administração e Comércio Exterior, Criciúma, SC, Brasil.

Guerra, R. M. A., Silva, M. S., \& Tondolo, V. A. G. (2014). Planejamento das necessidades de materiais: ferramenta para a melhoria do planejamento e controle da produção. Revista Gestão da Produção Operações e Sistemas, 9(3), 43.

Pires, J. G. (2013, Outubro). Aprendizagem organizacional através da metodologia de solução de problemas MASP. Simpósio de Excelência em Gestão e Tecnologia, Resende, RJ, Brasil. 
Citação (APA): Gaigher, H. A. \& Feroni, R. de C. (2021). Aplicação da metodologia de análise e resolução de problemas (MASP) em uma indústria montadora automotiva. Brazilian Journal of Production Engineering, 7(5), 183-193.

Rezende, D. M., da Silva, J. G., \& de Alencar, D. B. Application of MASP to Paper Waste Control in a Manaus X Institution. International Journal for Innovation Education and Research, 7(10), 663-677.

Rodrigues, W. L. H. P., \& SANTIN, N. J. (2004). Gerenciamento da cadeia de suprimentos. Revista Integração, (37), 97-102.

Santos, O. S., Pereira, J. C. S., \& Okano, M. T. (2012). A implantação da ferramenta da qualidade MASP para melhoria contínua em uma indústria vidreira. Caleidoscópio, 4(1), 6-23.

Santos, M. C., \& Gonçalves, A. T. P. (2016). Aplicação da Metodologia de Análise e Solução de Problemas-MASP na logística de uma grande rede varejista. Revista Gestão da Produção Operações e Sistemas, 11(4), 21.

Tanna, J., \& Vyas, A. (2017). Case Study on Manufacturing Resources Planning. Claro: Journal of Engineering, 25(3), 277-289.

Treter, F. M., Ten Caten, C. S., \& Tinoco, M. A. C. (2013). Utilização da análise de causa raiz e 8D nos atrasos de entrega de ordens de compra. Ingeniería Industrial. Actualidad y Nuevas Tendencias, 4(13), 63-79.

Vieira, D. G., Lima, G. B. A., \& Sant'Anna, A. P. (2015). Método de solução de problemas na gestão de suprimentos: utilização de regressão logística para análise das causas de atrasos no recebimento de materiais. Exacta, 13(1), 115-131. 